\title{
A High Voltage Gain Step-up Resonant DC-DC Converter Topology with Reduced Switch Count
}

\author{
A Sowmya ${ }^{1} \mid$ Dr. D Murali ${ }^{2}$
}

1PG Scholar, Department of EEE, Government College of Engineering, Salem, Tamil Nadu, India.

${ }^{2}$ Associate Professor, Department of EEE, Government College of Engineering, Salem, Tamil Nadu, India.

To Cite this Article

A Sowmya and Dr. D Murali, "A High Voltage Gain Step-up Resonant DC-DC Converter Topology with Reduced Switch Count", International Journal for Modern Trends in Science and Technology, Vol. 05, Issue 12, December 2019, pp.-26-31

\section{Article Info}

Received on 18-November-2019, Revised on 06-December-2019, Accepted on 15-December-2019, Published on 21-December-2019.

\section{ABSTRACT}

The resonant converters have attracted a lot of attention because of their high efficiency and low switching losses. This paper presents the analysis of a high voltage gain non-isolated step-up DC-DC converter topology using resonant technology. The proposed converter configuration has reduced number of power semiconductor switches compared to the existing isolated converter topology having four semiconductor switches. The proposed topology employs capacitor-inductor-capacitor (C-L-C) resonant circuit configuration. The size of the proposed converter and the losses in the converter are greatly reduced. Both the converters with resonant components are simulated in Matlab/Simulink platform to validate their performance. The time-domain simulation results demonstrate that the proposed non-isolated converter gives improved voltage gain compared to the existing two-stage isolated resonant DC-DC converter.

KEYWORDS: $C-L-C$ configuration, DC-DC converter, Matlab/Simulink, Resonant technology, Time-domain simulation results, Voltage gain.

Copyright (C) 2019 International Journal for Modern Trends in Science and Technology

DOI: https://doi.org/10.46501/IJMTST051205

\section{INTRODUCTION}

There are certain applications, such as renewable energy, photovoltaic arrays and fuel cell stacks, automobile electrical systems, and uninterruptible power systems, which require high voltage gain and efficiency based power converters [1]. Two step-up converters can be cascaded to realize a high voltage gain [2]. In cascaded scheme, the final output voltage is only regulated by the duty-ratio of the boost pre-regulated converter. Due to the hard-switching operation in the pre-regulated stage, the efficiency is limited and it is hard to be highly promoted.

The input-parallel-output-series (IPOS) architectures for the combined converters to achieve high voltage gain are proposed by some authors in [3]. These architectures are responsible for the increase of cost and circuit size with the reduction of reliability. The concept of high-step-up coupled-inductor boost converters is given by some authors to achieve high voltage gain [4]-[6]. The coupled-inductor approach makes the design process of the magnetic component complex, especially under high turns-ratio situations. The energy stored in the leakage inductor would also result in high spikes. An interleaved boost converter with a Bifold Dickson voltage multiplier suitable for interfacing low-voltage renewable energy sources to high-voltage distribution buses and other applications that require a high voltage gain conversion ratio is presented in [7]. However, 
high-order voltage- multiplier circuits result in increase of cost, circuit size and power loss [8].

In recent years, resonant converters have become more popular and are also widely applied to achieve a high voltage gain. One key attractive characteristic is that a resonant converter can easily achieve high efficiency and allow high frequency operation with their intrinsic wide soft-switching ranges. Hence, Zero Current Switching (ZCS) or Zero Voltage Switching (ZVS) can be easily realized during switching transitions. The ZVS reduces converter-generated Electro-Magnetic Interference (EMI) and ZCS is used to commutate the semiconductor switches. The LC Series Resonant Converter (SRC) has a variety of Continuous Conduction Modes (CCMs) and Discontinues Conduction Modes (DCMs) [9]. In addition, the SRC is hard to regulate the output voltage under light load conditions while the LC Parallel Resonant Converter (PRC) is hard to regulate the output voltage under heavy load conditions. The LLC resonant converter is attractive and shows a lot of unique improvements [10]. However, the design process of an LLC transformer needs a lot of attention to obtain a satisfactory compromise between the leakage and magnetizing inductances [11]. The power loss caused by the circulating current associated with magnetizing inductance is large when the switching frequency is far from the resonant frequency. Moreover, in SRC, LCC and LLC converters, the low input voltage situations may lead to the use of more bulky resonant capacitors in parallel to improve the efficiency.

A DC/DC converter topology for charging high voltage bulk capacitors for pulsed load applications is presented in [12]. This converter is capable of efficiently transferring power from $30 \mathrm{~V}$ input to a capacitor charging from $0 \mathrm{~V}$ to $6 \mathrm{kV}$. An isolated high step-up converter with secondary-side resonant loops is proposed and analyzed in [13]. By placing the resonant loops on the secondary side, the current stress for the resonant capacitors is greatly reduced. The power loss caused by the equivalent series resistance of the resonant capacitor is also decreased. Clamp diodes in parallel with the resonant capacitors ensure a unique DCM in the converter. The reverse-recovery problems of diodes are also alleviated by the leakage inductor. This high step-up converter is able to produce only a $400 \mathrm{~V}$ DC output with a $35 \mathrm{~V}$ - $42 \mathrm{~V}$ input DC voltage. A resonant converter topology, comprising of a half-bridge inductor-capacitor-inductor (L-C-L) resonant inverter and a bridge rectifier, is proposed in [14]. This converter is able to produce only $12 \mathrm{~V}$ DC with a input voltage of $24 \mathrm{~V}$. A new arrangement of loaded resonant converter for DC-DC energy conversion applications is analyzed in [15]. This circuit consists of a capacitor-inductor-capacitor (C-L-C) resonant inverter and a half-bridge diode rectifier. This configuration is able to produce only $21 \mathrm{~V}$ output DC voltage with $24 \mathrm{~V}$ input DC voltage. For the purpose of finding a high efficiency step-up converter suitable for the low input voltage field, an improved configuration of step-up converter comprising of C-L-C resonant inverter and a bridge rectifier with clamp diodes is proposed in this paper. The $\mathrm{C}-\mathrm{L}-\mathrm{C}$ resonant converter is more preferable than the L-C-L configuration because it improves the energy conversion efficiency and also reduces the equipment cost. The proposed configuration has the elimination of two semiconductor switches and a transformer.

The structure of the research work presented in this paper is organized in the following sequence: The various modes of operation of the existing LC series resonant converter are briefly explained in section 2. The proposed improved converter configuration is presented in section 3. The simulation results and discussions are given in section 4 . This is followed by the conclusion in the concluding section 5 .

\section{EXISTing Resonant Converter Configuration}

A schematic of the existing converter with clamp diodes on the secondary side is shown in Fig. 1 [13]. The various modes of operation are illustrated in Fig. 2, Fig. 3, Fig. 4, Fig. 5, and Fig. 6 respectively. For the sake of simplicity, the converter is called "LC-DS", which means "LC resonant converter with clamp Diodes on the Secondary side". Therefore, the LC-DS is symmetrical to the LC-DP. The input structure consists of four active switches $\left(\mathrm{S}_{1}-\mathrm{S}_{4}\right)$, which forms a full-bridge configuration to fully utilize the input voltage. On the secondary side of the transformer, two rectifier diodes $\left(\mathrm{D}_{1}\right.$ and $\left.\mathrm{D}_{2}\right)$ and two clamp diodes $\left(D_{3}\right.$ and $\left.D_{4}\right)$ with paralleled resonant capacitors $\left(\mathrm{C}_{1}\right.$ and $\left.\mathrm{C}_{2}\right)$ form the rectifier stage. The leakage inductor $\mathrm{L}$ is inserted on the secondary side. The resistance of the load resistor is denoted by $\mathrm{R}_{\mathrm{L}}$. A capacitor $\mathrm{C}_{0}$ is placed at the output. As a result, the output voltage contains negligible harmonics of the switching frequency. The resonant process can be determined by the leakage inductor and the two resonant capacitors. 'N' denotes the transformer turns-ratio. The 
following assumptions are made for the configuration:

(i). All of the component models are ideal and the parasitic parameters are not considered here.

(ii). The switching dead-time is neglected.

(iii). The magnetizing inductor $\mathrm{L}_{\mathrm{m}}$ is large enough and the magnetizing current is neglected.

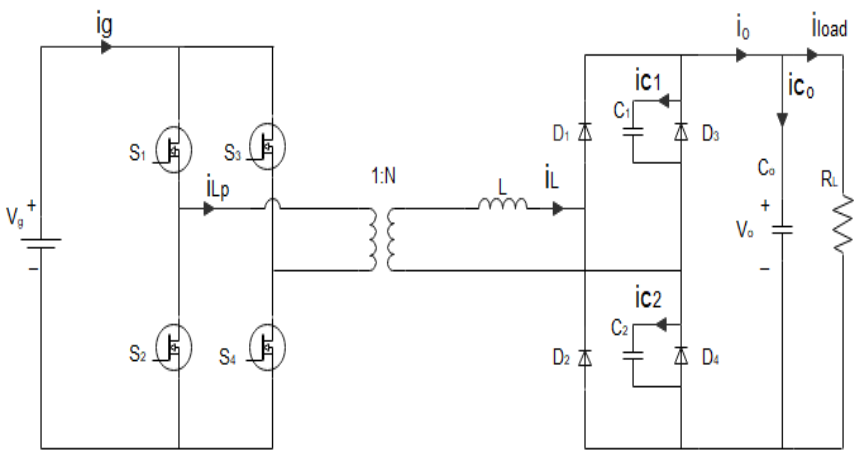

Fig. 1 Existing converter configuration

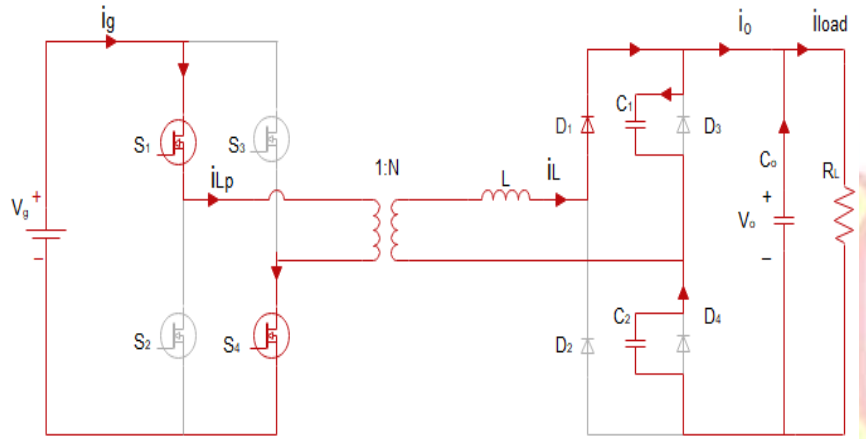

Fig. 2 Conduction path during Mode $I\left(t_{0}<t<t_{1}\right)$

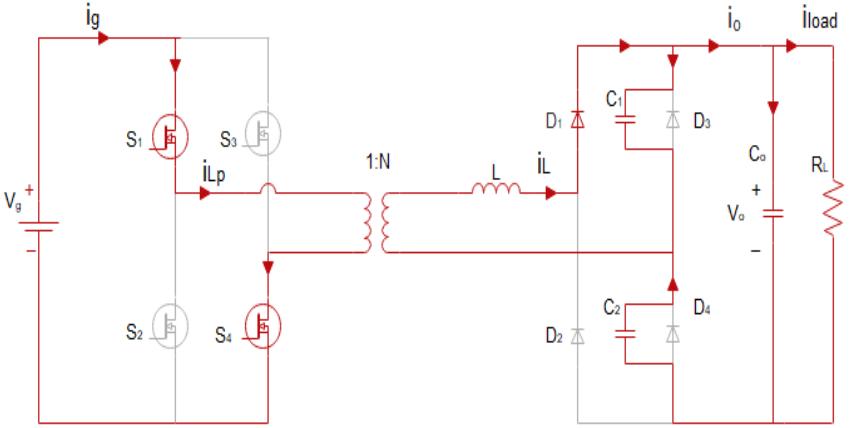

Fig. 3 Conduction path during Mode II $\left(t_{1}<t<t_{2}\right)$

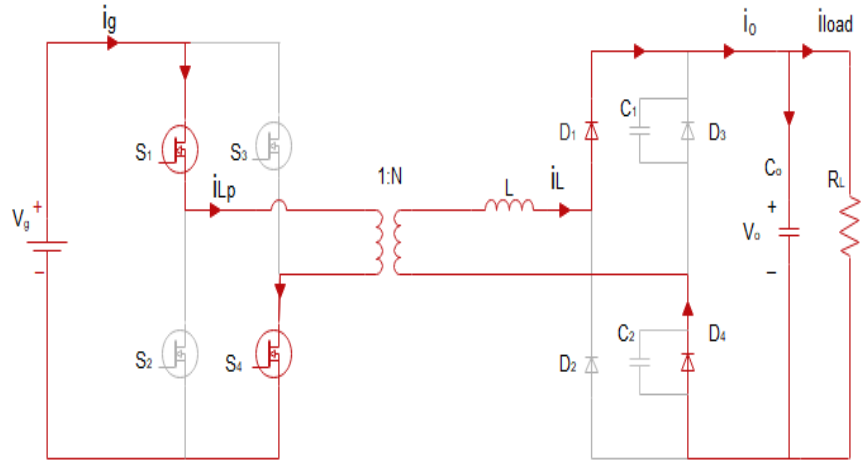

Fig. 4 Conduction path during Mode III $\left(t_{2}<t<t_{3}\right)$

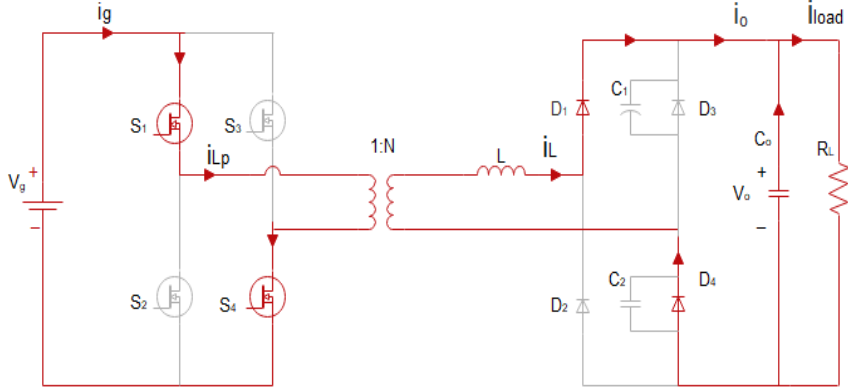

Fig. 5 Conduction path during Mode IV $\left(t_{3}<t<t_{4}\right)$

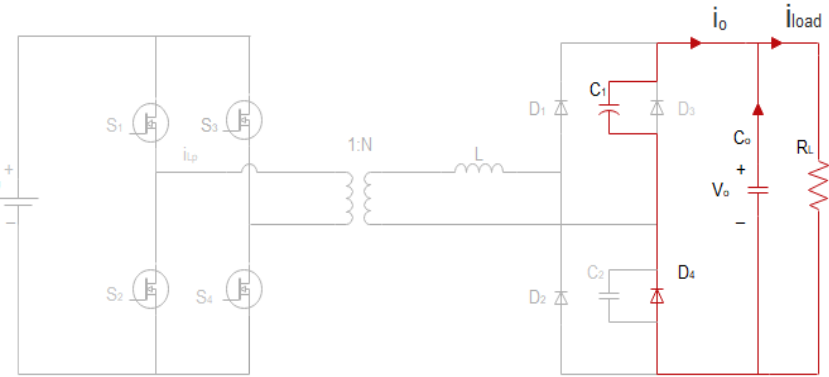

Fig. 6 Conduction path during Mode $V\left(t_{4}<t<t_{5}\right)$

\section{Proposed Resonant Converter Topology}

The proposed converter topology is shown in Fig. 7. In the proposed converter configuration, the step-up transformer is replaced by resonant tank circuit and the two switches are replaced by the inductors. Hence, the size of the converter is reduced and the cost is low compared to the existing converter. By having the inductors along with the switches, the voltage gets boosted up in the circuit.

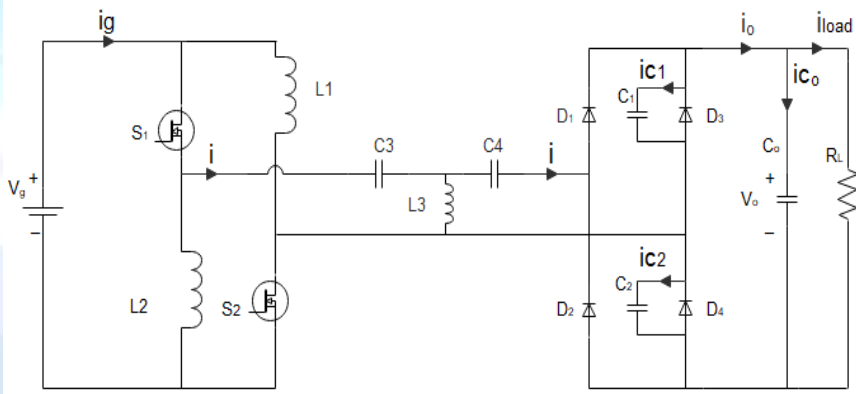

Fig. 7 Proposed converter topology MODE 1:

The Fig. 8 shows the conduction path of the converter through the resonant components during Mode 1 . The switch $\mathrm{S}_{2}$ is excited before the period $\omega_{0} t_{0}$. The switch $\mathrm{S}_{1}$ will be turned on at $\omega_{0} t_{0}$

. The current from resonant circuit is negative and it will flow through the freewheeling diode $\mathrm{D}_{1}$ to switch on $\mathrm{S}_{1}$. Hence, the switches are turned on naturally at zero voltage and zero current instants. Therefore, the current through the switch which is in conduction mode will be negative before turn on and positive before turn off. 


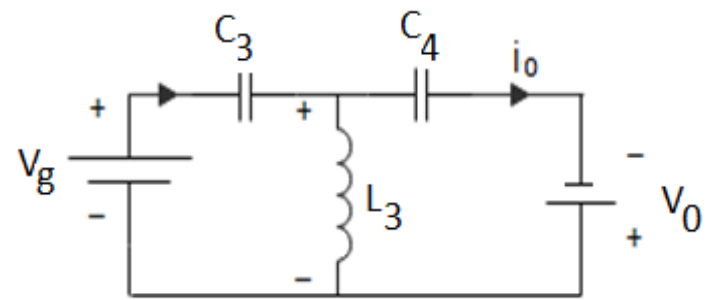

Fig. 8 Conduction path through the resonant circuit during Mode 1

MODE 2:

During this mode, the current through resonant tank circuit is transforming from negative to zero at $\omega_{0} t_{1}$. The switch $\mathrm{S}_{1}$ is commutated to turn off, forcing the current to flow through the freewheeling path $\mathrm{D}_{2}$. The Fig. 9 shows the conduction path of the converter through the resonant components during Mode 2. The positive DC input voltage applied across the tank circuit causes the resonant current that flows through the switches to go to zero.

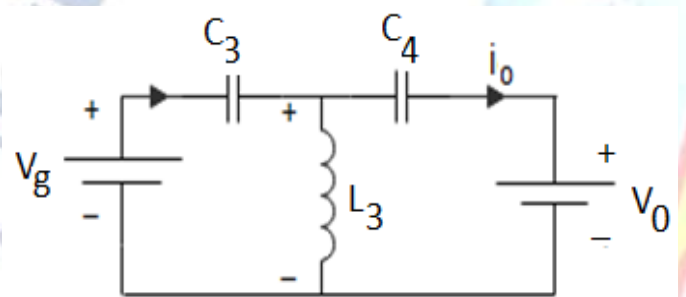

Fig. 9 Conduction path through the resonant circuit during Mode 2

\section{MODE 3:}

Now a turn-off trigger signal is given to the gate of $\mathrm{S}_{1}$ which is in conduction mode. The inductor current then spontaneously turns off $\mathrm{S}_{1}$ from active mode to flow through freewheeling path $\mathrm{D}_{2}$. This mode starts when diode $\mathrm{D}_{2}$ starts conducting. The equivalent arrangement for this mode is shown in Fig. 10.

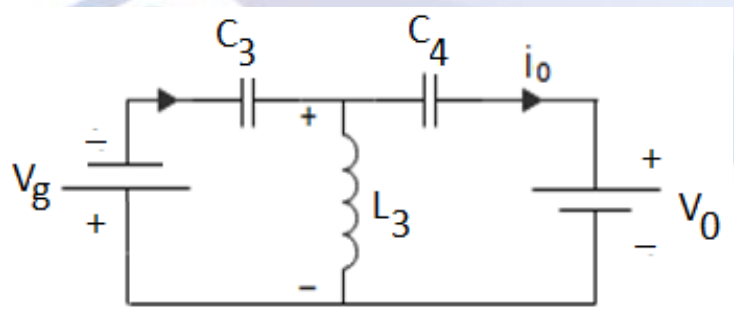

Fig. 10 Conduction path through the resonant circuit during Mode 3

MODE 4:

When voltage across the resonant tank circuit is positive, the rectifier diodes come to conduction mode and the input voltage is applied to the load through these diodes. Similarly, when the direction of current flow is changed in resonant tank circuit, these diodes are turned off because of the reverse voltage. When the trigger signal $\mathrm{V}_{\mathrm{g}}$ is applied, the excitation starts and the process is repeated from Mode 1. The Fig. 11 shows the conduction path of the converter through the resonant components during Mode 4.

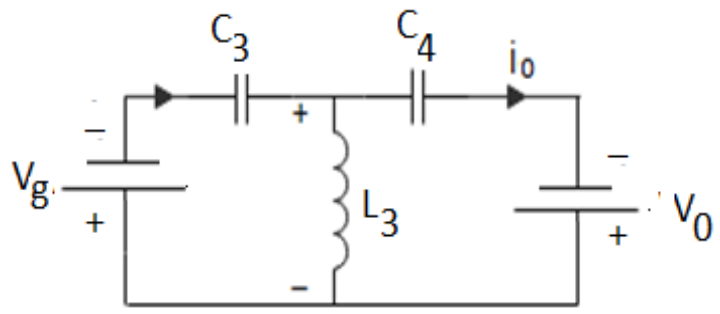

Fig. 11 Conduction path through the resonant circuit during Mode 4

\section{Simulation Results and Discussion}

The existing isolated resonant converter topology is simulated in Matlab / Simulink environment as shown in Fig. 12. There are two stages in the existing scheme; the first stage is DC-AC conversion, the second stage is AC-DC conversion. The transformer with turns-ratio of $1: 6$ and magnetizing inductance of $73 \mu \mathrm{H}$ isolates the two stages. The value of inductance of the series inductor is $30 \mu \mathrm{H}$. The resonant capacitors $\mathrm{C}_{1}$ and $\mathrm{C}_{2}$ each have $30 \mathrm{nF}$ capacitance. The output capacitor $\mathrm{C}_{0}$ has $73 \mu \mathrm{F}$ capacitance. The load resistance $R_{L}$ is $2 \mathrm{k} \Omega$. The switching frequency is $30 \mathrm{kHz}$. The existing topology gives a DC output voltage of $400 \mathrm{~V}$ with an input DC voltage of $40 \mathrm{~V}$ with transformer ratio of $1: 6$. The duty cycle ratio of the switches is taken as $50 \%(\mathrm{~d}=0.5)$. When the duty cycle is in the range between 0.5 and 0.8 , the output voltage level may get boosted up to 10 times the input voltage. The output current is of the order of 0.2 A. The waveforms of output voltage and output current are shown in Fig. 13 and Fig. 14.

The simulation of the proposed non-isolated resonant converter configuration is carried out in Matlab / Simulink platform as shown in Fig. 15. This configuration also has two stages; the first stage is DC-AC conversion, the second stage is AC-DC conversion. A resonant circuit is employed between the two stages. The inductors on the input side have inductance of $180 \mu \mathrm{H}$ each. The resonant components have values of $\mathrm{C}_{3}=\mathrm{C}_{4}=10 \mu \mathrm{F}$ and $\mathrm{L}_{3}$ $=410 \mu \mathrm{H}$. The capacitors $\mathrm{C}_{1}$ and $\mathrm{C}_{2}$ across the diodes have capacitance of $30 \mathrm{nF}$ each. The output capacitor $\mathrm{C}_{0}$ has $80 \mu \mathrm{F}$ capacitance. The load resistance $R_{L}$ is $2 \mathrm{k} \Omega$. The switching frequency is $30 \mathrm{kHz}$. The resonant frequency $\left(f_{r}\right)$ of the C-L-C circuit is calculated as $22 \mathrm{kHz}$. 


$$
f_{r}=\sqrt{\frac{1}{L_{3}}\left(\frac{1}{C_{3}}+\frac{1}{C_{4}}\right)}=22 \mathrm{kHz}
$$

An input DC voltage of $40 \mathrm{~V}$ is given to the circuit, with the duty cycle ratio of the switches as $80 \%(\mathrm{~d}=0.8)$. A DC output voltage of around $1000 \mathrm{~V}$ is obtained when the duty cycle is varied between 0.5 and 0.8 . The voltage gain of the proposed converter is almost 25 times the input voltage. Moreover, in the proposed converter system, the switches are reduced to two thereby reducing the losses and the size of the converter. The gate pulse given to the switches of the converter is as shown in Fig. 16. The waveforms of output voltage and output current for the proposed converter are shown in Fig. 17 and Fig. 18. The output current is of the order of $0.5 \mathrm{~A}$.

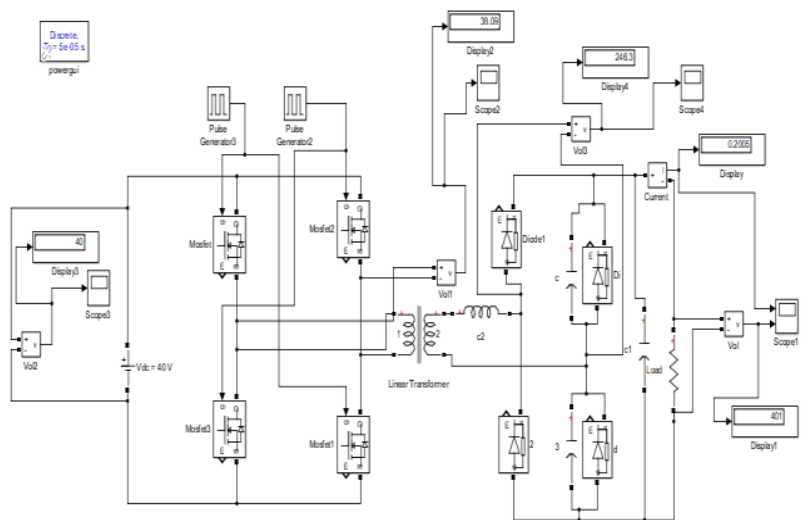

Fig. 12 Simulation diagram of the existing resonant converter topology

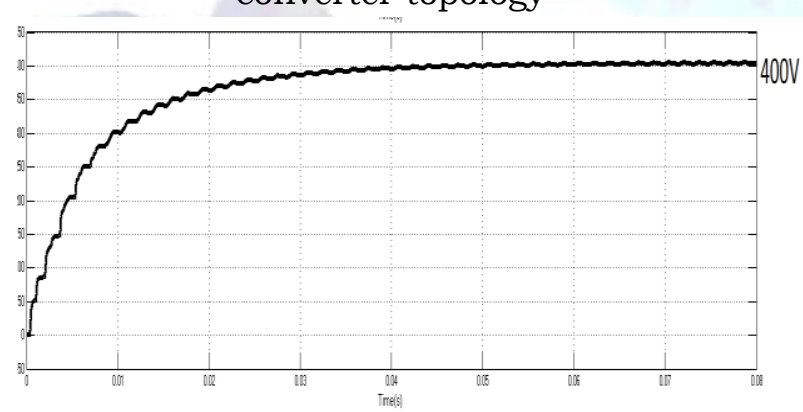

Fig. 13 Output voltage waveform of the existing converter topology

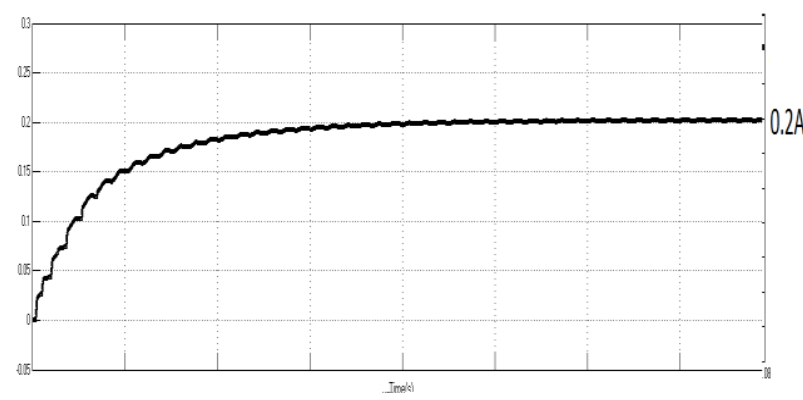

Fig. 14 Output current waveform of the existing converter topology

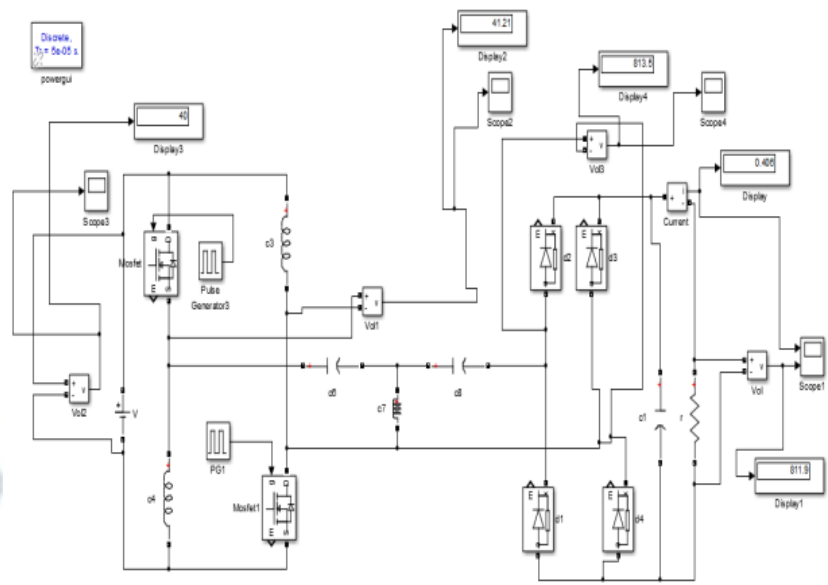

Fig. 15 Simulation diagram of the proposed resonant converter configuration

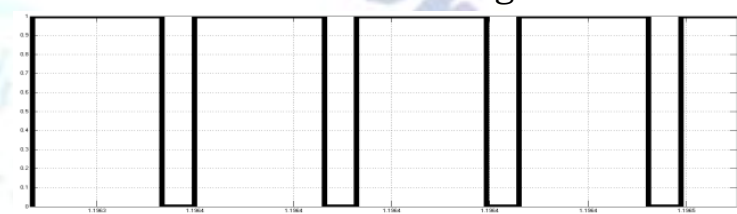

Fig. 16 Gate pulse to the switches of the proposed converter

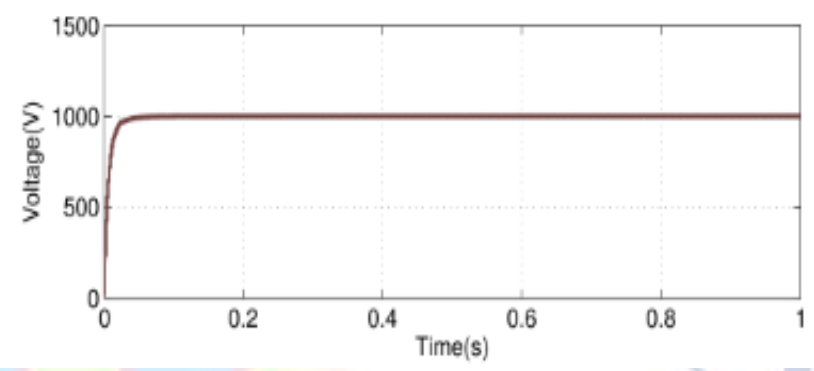

Fig. 17 Output voltage waveform of the proposed converter topology

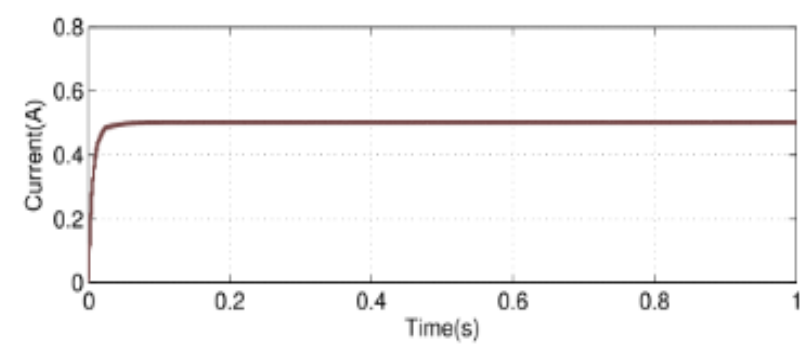

Fig. 18 Output current waveform of the proposed converter topology

The current and voltage waveforms of the resonant capacitor $\mathrm{C}_{3}$ and $\mathrm{C}_{4}$ for the proposed converter configuration are shown in Fig. 19, Fig. 20, Fig. 21, and Fig. 22 respectively.

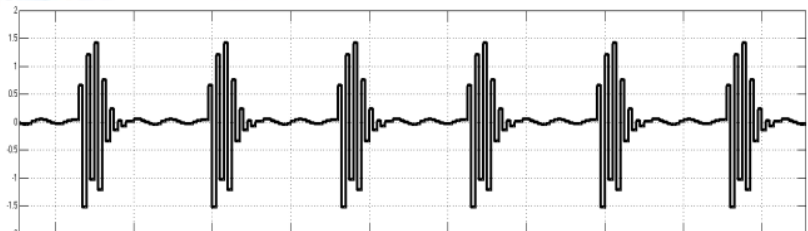

Fig. 19 Waveform of current through the resonant capacitor $\mathrm{C}_{3}$ 


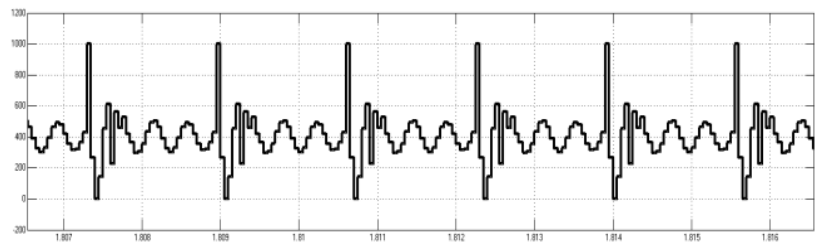

Fig. 20 Waveform of voltage across the resonant capacitor $\mathrm{C}_{3}$

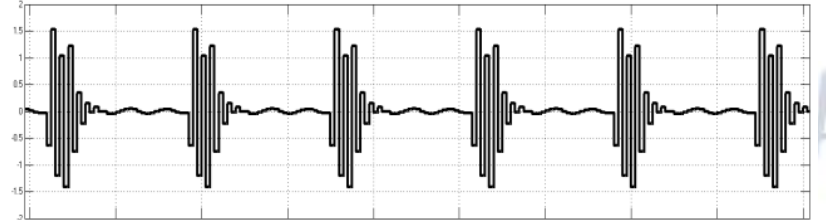

Fig. 21 Waveform of current through the resonant capacitor $\mathrm{C}_{4}$

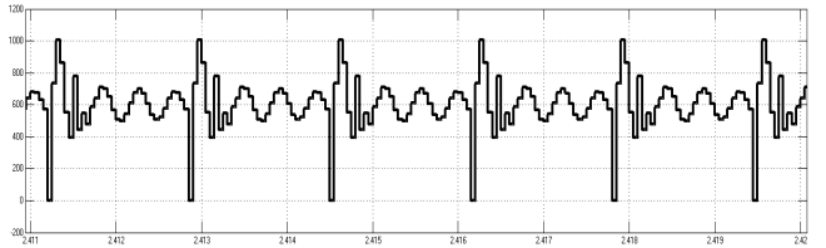

Fig. 22 Waveform of voltage across the resonant capacitor $\mathrm{C}_{4}$

\section{v. Conclusion}

In this paper, the performance analysis of a DC-DC resonant converter with clamp diodes on the secondary side is proposed. The proposed converter configuration is compared with that of the existing topology. The digital simulations are carried out in Matlab/Simulink environment to validate the performance of the proposed converter. The results demonstrate that the proposed converter configuration has the capability to produce an output voltage which is almost 25 times the input voltage, whereas the existing converter topology could produce the output voltage which is only 10 times the input voltage. Hence, the proposed converter configuration can improve the voltage gain of the system. Moreover, in the proposed non-isolated converter topology, the number of power semiconductor switches is reduced thereby the switching losses, the voltage stresses and the current stress of the resonant capacitors are significantly reduced. In both the existing and proposed converter configurations, the switches are turned on and off by the conventional PWM technique. Therefore, the non-isolated configuration is suitable to realize high DC voltage gain and slightly improved efficiency.

\section{REFERENCES}

[1] J. T. Bialasiewicz, "Renewable energy systems with Photovoltaic power generators: Operation and Modeling",
IEEE Transactions on Industrial Electronics, Vol. 55, No. 7, pp. 2752-2758, 2008.

[2] D. H. Kim, H. W. Kim, J. H. Park, and H. J. Jeon, "High efficiency high-step-up single-ended DC-DC converter with small output voltage ripple", Journal of Power Electronics, Vol. 15, No. 6, pp. 1468-1479, 2015.

[3] T. Li and L. Parsa, "Design, control, and analysis of a fault-tolerant soft-switching DC-DC converter for high-power high-voltage applications", IEEE Transactions on Power Electronics, Vol. 33, No. 2, pp. 1094-1104, 2018.

[4] H. Liu, H. Hu, H. Wu, Y. Xing, and Issa Batarseh, "Overview of high-step-up coupled-inductor boost converters", IEEE Journal of Emerging and Selected Topics in Power Electronics, Vol. 4, No. 2, pp. 689-704, 2016.

[5] Y. P. Hsieh, J. F. Chen, T. J. Liang, and L. S. Yang, "Novel high step-up DC-DC converter with coupled-inductor and switched-capacitor techniques", IEEE Transactions on Industrial Electronics, Vol. 59, No. 2, pp. 998-1007, 2012.

[6] W. Liang, X. Hu, H. Chen, G. Wu, M. Zhang, and G. Tan, "High-voltage-gain DC-DC converter with three-winding coupled inductor", Chinese Journal of Electrical Engineering, Vol. 5, No. 1, pp. 10-23, 2019.

[7] A. Alzahrani, M. Ferdowsi, and P. Shamsi, "High-voltage-gain DC-DC step-up converter with Bifold Dickson voltage multiplier cells", IEEE Transactions on Power Electronics, Vol. 34, No. 10, pp. 9732-9742, 2019.

[8] M. Fourouzesh, Y. P. Siwakoti, S. A. Gorji, F. Blaabjerg, and B. Lehman, "Step-up DC-DC converters: A comprehensive review of voltage-boosting techniques, topologies, and applications", IEEE Transactions on Power Electronics, Vol. 32, No. 12, pp. 9143-9178, 2017.

[9] R. W. Erickson, "Fundamentals of Power Electronics", 2nd Edition, USA: Kluwer Academic Publishers, Chapter 19, pp. 740-752, 2000.

[10] M. Shang and H. Wang, "LLC converter with reconfigurable voltage multiplier rectifier for high voltage and wide output range applications", IECON 2017 - 43rd Annual Conference of the IEEE Industrial Electronics Society, pp. 1279-1285, 2017.

[11] H. Wu, X. Jin, H. Hu, and Y. Xing, "Multielement resonant converters with a notch filter on secondary side", IEEE Transactions on Power Electronics, Vol. 31, No. 6, pp. 3999-4004, 2016.

[12] J. Elmes, C. Jourdan, O. A. Rahman, and I. Batarseh, "High-voltage, high-power-density DC-DC converter for capacitor charging applications", 24th Annual IEEE Applied Power Electronics Conference and Exposition, 2009.

[13] P. Jia and Y. Yuan, "Analysis and implementation of LC series resonant converter with secondary side clamp diodes under DCM operation for high step-up applications", Journal of Power Electronics, Vol. 19, No. 2, pp. 363-379, 2019.

[14] R. Halakurki and R. Gollapalli, "Resonant converter for the application of DC-to-DC energy conversions", International Journal of Advanced Research in Electrical, Electronics and Instrumentation Engineering, Vol. 3, No. 10, pp. 12547-12555, 2014.

[15] M. Bhargavi, S. Sridhar, and T. Ravi kumar, "A new arrangement of resonance tank circuit for DC-to-DC energy converting applications", International Journal of Engineering Research \& Technology, Vol. 3, No. 11, pp. 398-403, 2014. 